\title{
Use of Structured Portfolio in Surgical Training of Postgraduate Medical Education
}

\author{
Shahid Hassan \\ Department of Medical Education/ORL-HNS, School of Medical Sciences, Universiti Sains Malaysia
}

\begin{abstract}
Background: Reflection on the process of learning is an essential ingredient in transforming novice into expert learners. Learning to compile portfolio encourages reflective skills, which help students to work systemically in translating metacognition into self-regulatory control in order to adjust their action and monitor their learning objectives. Introducing to compile portfolio in the early years of postgraduate training is an effective tool to stimulate students' reflective abilities. Reflective learners are better motivated than the conventional learners to take the responsibilities as researcher in future. Reflective skills achieve both learning in right direction and learning for whole life. However, use of formal methods of reflective portfolio to monitor the learning objectives is an uncommon practice in postgraduate training, primarily due to intensive time and labor required. Challenged with those constraints in Master's of Surgery Program of Otolaryngology and Head-Neck Surgery in School of Medical Sciences at Universiti Sains Malaysia, a structured self-reflective portfolio was introduced to determine its feasibility and acceptance among supervisors and trainees. Portfolio was practiced as one of the tool for formative assessment and for making recommendations to certify independent thyroid surgery allowed to practice in future.
\end{abstract}

Methodology: A self-reflective structured portfolio was introduced to monitor the learning objectives in trainees of 2007 cohort, using a model as "mentor-system for authentic and structured learning with self-reflective assessment" (MASSRA). Initially a semi-structured portfolio comprising of 12 items and guidelines to compile a portfolio was followed by a structured format in training of thyroid module in sub-specialty of Head and Neck Surgery. Mentoring was organized by putting onementor verses 9 students to provide general pastoral guidance to compile portfolio as two entries a year. Mentors held the counseling session with student twice a year after evaluating the portfolios to monitor their progress. Besides, candidates were also observed for their performance in thyroid surgery during a 4-years training program. Those identified with problems for their level of training were referred to "Joint Committee for Surgical Training" comprising of 3 supervisors from Head and Neck Surgery Sub-specialty and a chairman supposedly the head of the department. 7 randomly selected students were also interviewed for direct feedback to evaluate this model.

Result: 28 trainees at different level of their training compiled a self-reflection structured portfolio minimum twice a year with instructional feedback from the mentor, which was used as a tract for their personal development plan (produced by each trainee) for training in thyroid surgery. Initial analysis of portfolio revealed interesting feedback from the trainees reflecting on their knowledge, surgical skills and attitude towards thyroid surgery seen in tables 2-4.

Conclusion: Self-reflections about each structured items in portfolio-helped trainees to identify their problems, seek mentors guidance and work systemically to help adjust their actions by revising learning objectives. Though time and labor intensive, portfolio was rated as feasible and practical.

Keywords: Structured Surgical Training, Self-reflection, Portfolio, Assessment and Evaluation 


\section{Introduction}

Advance learning in medical education expects expert learners in training. The outcome of an effective postgraduate training depends upon how the learners reflect on their abilities. Self-knowledge and superior monitoring skills simply reflect the accumulation of greater domain knowledge (1). It is the monitoring and self-regulatory skills that enables the learners to know, what is important and how, when and why is it important to know. The acquired knowledge enables them to use it in a similar situation arising in real life. While reflecting on their learning experiences postgraduate trainees can effectively combine the knowledge of task requirement, own learning habit and selfregulatory strategies. Learners lacking in self-reflective-abilities cannot estimate whether they have comprehended and mastered the information presented to them as knowledge or as skill. Compiling, reviewing and monitoring self-reflection creates a documented evidence for trainees to execute their personal development plan to meet the outcome objectives of training.

Collecting students work in folders has long been practiced and a purposeful collection of pieces of student work makes it student's portfolio (2). A student's portfolio is usually a self- portrait developed with the guidance of feedback from teachers and peers carrying special purpose to monitor student's own progress (2). Portfolio is a document in which teaching, learning and assessment are enmeshed in a single activity and is completed by the students themselves to reflect on their progress in a learning environment. Although time consuming and requires substantial effort on part of student and teacher it benefits instruction and learning as well as assessment if utilized carefully.

Key steps in implementing portfolio are (2):

1. To specify purpose of introducing the practice of portfolio in curriculum such as, instruction, assessment, accomplishment and progress.

2. To provide guidelines for selecting portfolio entries keeping flexibility about the use that will be made of portfolio for example, persons to have access to portfolio, appropriate work to be included and criteria to be used in evaluation.

3. To define students role in selection of entries and their self-evaluation which includes, student's involvement on reflection entries and self-evaluation and teachers guidelines based on purpose and goals of learning.

4. To specify criteria to be practiced in evaluation of portfolio entries such as, elaborate link to any specified purpose in portfolio, analytic scoring rubrics if formative assessment, holistic scoring rubrics for summative assessment. Rating scales (if used) must be specified very clearly

5. To specify criteria for evaluating overall structure of portfolio such as, rating of the organization, training and trainers or quality of self-reflection however, concealing the identity of student and criteria used in evaluation.

6. To use portfolios for instruction and for the communication purposes so as to make it dynamic after monitoring the student's performance, observing the ongoing work and evaluating the ongoing planning. Selfreflection can also be used as a window to classroom since it provides mechanism for communicating with parents about student's development and students with their self-evaluation skills.

Considering the potential strength of portfolio, it can be readily integrated with instructions to provide opportunity and to show what students can do. It encourages students to become refractive learners. It also help trainees to set new learning objectives, work in collaboration with teacher and peer students and to provide 
formative feedback reflecting on student's progress.

The use of portfolio in postgraduate training and continuous professional development has been found an effective tool for reminding, planning, tracking and encouraging reflection (4). Portfolio as an assessment tool may be problematic nevertheless it is specially suited for coaching and assessing authentic learning at more senior level (5) This can be achieved precisely well, utilizing a portfolio practice with a backup monitoring of supervisor at postgraduate level. At postgraduate level trainees are required to develop practical knowledge and strategies that will guide them to perform as competent doctors. A combination of contextualized and authentic learning with just-in-time instructions will enable a postgraduate to acquire the skills they need to learn before entering into independent medical practice.

Thoroughly planned introduction of completing portfolio in the early years of medical education is an effective tool to stimulate students' reflective abilities. Reflective learners are better motivated than the conventional learners to take the responsibilities as researcher in future. However, most of the trainees in postgraduate program have had no experience of reflective portfolio since many medical schools in undergraduate medical education in Malaysia do not practice learning portfolios for self-assessment. Formative assessment is though practiced in most of these medical schools in undergraduate and postgraduate curriculum but the measurement tools utilized are often the same as those used in summative assessment. An important purpose of practicing formative assessment in medical education is to provide just-on-time instructional feedback to students. Compiling self-reflective portfolio also serves that purpose effectively well if properly executed. As the continuous medical education has become imperative for medical profession, the major task of medical schools' now is to help create learners who know how to learn. Reflective skills achieve both learning in right direction and learning for entire life.

Keeping in view the utility of formative assessment in medical education, we have proposed a student and faculty friendly "mentor-system for authentic, structured learning with self-reflective assessment" (MASSRA) model for practicing portfolio, which is instructive and meaningful with regard to learn and how to learn to reflect on own progress. The model purposefully designed for competent learning in postgraduate program is based on the concepts of guaranteeing independent surgical practice to trainees in specific modules in surgery on recommendations of the immediate supervisors and passing of summative assessment, similar to board certified examination models. While practicing this model students can also achieve the out-come objectives of their learning goals in a module. This model has been successfully employed in structuring the thyroid surgical skills training of Masters in Otolaryngology and Head- Neck Surgery in School of Medical Sciences at University Science Malaysia. Outcome experience of this study trial is presented together with the remarks from randomly selected student's interview. A semi-structured format (see appendix) to start with compiling of portfolio is followed by structured portfolio (see table 1-4) and is compiled minimum twice a year after operating on thyroid patients. Postgraduate trainees compile their experiences of acquired competence as the self-reflective analysis after performing various types of thyroid surgeries with or without supervision, which is subsequently evaluated by the clinical supervisors. Practice of compiling portfolio is expected to enhance the learning skills by trainees. It is also seen as part of strategy in making decision to award certification for independent practice in specific modules of surgical training (see figure 1 ) on receiving a positive observation report from the 
immediate supervisor and passing of summative assessment. The key components of MASSRA are:

M: Mentor-system, to coach the student in reorganizing their learning needs and to appreciate the value of evidence established in portfolio.

A: Authentic-learning, to stimulate the student's reflective-abilities in early phase of their apprenticeship learning with real patients in postgraduate studies in order to learn from practice of portfolio.

S: Structured-nature, to determine content and form of portfolio as guidelines for students to learn how to compile portfolio.

R: Reflective-abilities, to be able to practice as self-reflection organized around students learning needs.

A: Assessment-needs to combine with reflection in portfolio as the modest tool of an overall assessment program. Initially we recommend its implementation as a role in formative assessment used as a prerequisite to determine trainee's preparedness and eligibility to take the exit examination at the end of Phase II (year 4).

A detail account of these five components MASSRA model is as following:

Mentor-system: Regular discussion with students and mentor and comments from the peer's serves to stimulate self-reflection (8). Cooperation between learner and mentor will help recognizes students learning needs, setting up their learning schedule and validation of portfolio materials. Mentoring also provide opportunities to work up the emotional aspect and attitude to rightly appreciate value of evidence by learners. Literature on portfolio suggests that factors contributing to its effectiveness include a supportive mentor system (9). On the contrary a weakly structure portfolio with ambiguous purpose and lack of mentorship usually leads to frustrating situation in which students often do not know how to go about compiling a portfolio (10).

Authentic-learning: An authentic learning environment is one in which the cognitive demand i.e. critical thinking (problem solving skills) required are consistent with cognitive demands of the environment (real clinical scenario) to which a learner is exposed during learning. Once introduced in phase I, students can use portfolio initially for self-reflection-abilities and evaluation of their learning objectives. Trainees can relocate their objectives if required to improve learning with real patients and hands-on experience of actually performed operative procedures. Later after faculty development and student's awareness in compiling portfolio the same may gradually be brought into practice as an authentic document coupled with the personal experience to be used both, for formative assessment as well as for guaranteeing independent practice by graduating trainees in specific modules in surgery.

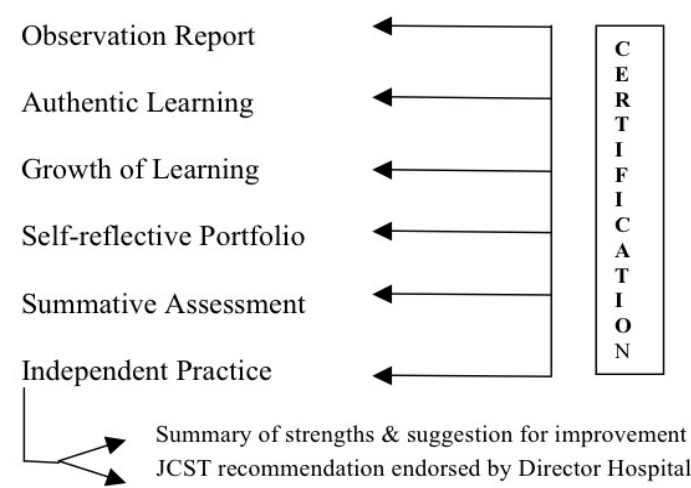

Figure 1: Hierarchy of competence-based training certifying a trainee capable of independent practice in surgical procedure.

Structure-format: How do we structure the portfolio really matters? For example very much prescribed content, value and structure provided will have little possibility to bring out personal qualities. Similarly, ticks off list that help to demonstrate expectations provide little freedom for students to write their own observations (11). Compared to this little or no structure 
provided for compiling portfolio will give the students hardly any idea how to compile portfolio and they may end up in frustration with a new portfolio system resulting in disorganized and irrelevant observation (12). What really matters is the student's ownership to stimulate self-reflection. Therefore we must organize portfolio around student's self-reflection practice.

Reflective-abilities: Outcome of knowing about the self-strengths and weaknesses help formulate new learning objective for coming period. This is possible after evaluating the performance with strong and weak points on each competence. This promotes critical and self-reflection skill in students.

Assessment-needs: Congruence between training and assessment is imperative (13). Assessments confined to declare pass or fail results of students become a nightmare for learners. Learning for assessment and assessment for learning should be abided in educational practice. It is generally believed that assessment based on portfolio makes it less valid and attempt to improve reliability makes it unrealistic. Reliability of assessment and use of portfolio for testing purpose results in corruption of portfolio (14). However, it is also experienced that compiling portfolio without a credit is ineffective. Assessment and reflection should combine in portfolio, albeit, as the modest part of entire assessment program as we presently practice. But, we must know what exactly is to be assessed in portfolio? We must appreciate this as an authentic material coupled with personal experience. Aim to improve reliability is a threat to validity, which can be countered by increasing the number of assessors but is expensive and logistically difficult to manage. However, standardization of portfolio format, utilization of the analytical criteria and improvisation of inter-rater reliability can improve reliability of portfolio as assessment. The type of assessment therefore should be holistic and quantitative with some degree of standardization and check and balance to have the anticipated result (15).

\section{Methodology}

A self-reflection portfolio on learning how to manage a surgical patient in thyroid surgery was introduced to invite trainee's comments as reflection on their own diagnostic, therapeutic and surgical skills. A semistructured portfolio with 12 items was provided with guidelines to explain each item (see appendix). The portfolio was initiated with trainee's introduction and their past experience in thyroid surgery. This was to let them know about their current knowledge, skills and attitude. Reflecting on expectations for role assigned gave supervisors an insight of trainee's attitude towards collaborative approach as a team member. Similarly knowing about the diagnostic workup, role-by-role personal plan and keenness to know the outcome testified trainee's interest and enthusiasm towards critical thinking skills. Previous training, surgical anatomy and apprehension about the role given were to reflect on their abilities as surgeon. Liking or disliking about performance as a team member and in relation to the cases performed was to reflect on their interest in thyroid training program and their role in the team. Analyzing own professional development and a need to change the learning objectives suggested trainee's enthusiasm in continuing surgical education. At the end each trainee was given a free hand to reflect on any aspect they think is left uncovered in this semi-structured self-reflection format. Mentoring was organized by putting onementor verses 9 students with their respective task as: 1) to help students compile a self-reflection portfolio as minimum two entries a year, 2) to provide general pastoral guidance, 3) to conduct counseling session with students minimum twice a year after analyzing their portfolios. 4) To refer problematic student to a "Joint Committee for Structured Training" (JCST) in 
Head and Neck and Thyroid Surgery comprising of three supervisors and a chairman supposedly the Head of the Department of ORL-HNS.

Final recommendations made by JCST to certify successful training in thyroid surgery was planned to be endorsed by the Director of the University Hospital at the end of year 4 on passing the exit exam. The assessment in thyroid surgery training was graded as insufficient, sufficient or with merit and was told to have no impact on candidates' summative assessment. All trainees in this program were informed to take the role they were eligible as per level of their training described in the protocol (see figure 2) for compiling the portfolio. The role assigned in protocol is to discipline the trainees and to avoid their unnecessary competing with each other for a position to perform surgery.

\section{Result}

A semi-structured portfolio (see appendix) was initially administered to 28 trainees at different level of their training to compile their self-reflection on structured surgical skills training program (see table 1) on thyroid surgery module at least twice a year. Trainees were divided into 3 groups with one mentor each to periodically analyze the self-reflective portfolios and provide instructional feedback, which was used as a tract for personal development plan (produced by each trainee) for training in thyroid surgery. Portfolio analysis revealed interesting feedback from the trainees (see table 2, 3 and 4).

The first evaluation of these portfolios was followed by a semi-structured interview of seven randomly selected trainees in April 2008 by the same committee (JCST). All students found themselves capable of compiling a portfolio as a self- reflectiveability after their exposure to different phases of thyroid surgery training. Adapting the portfolio in thyroid surgery module of postgraduate training in Otolaryngology and Head-Neck Surgery, supervisors found it feasible and worth practicing. Practice of portfolio also provided an evidence to what claim is made for postgraduate program in thyroid surgery, being structured and competence-based.

\section{Discussion}

Postgraduate medical education in many disciplines in Malaysia is being carried out without a written curricula and this is why a standardized method of teaching and learning in postgraduate training is hardly practiced. Competent specialist particularly in surgical and allied discipline is an expectation of all major stakeholders. Postgraduate trainees need to develop knowledge and practical skills and strategies to mastering those skills that ultimately will guide their performance as competent doctors. A combination of contextualized and authentic learning with just in-time instruction in theory and practical skills will enable a postgraduate trainee to acquire the skills required for their performance in medical practice. In clinical and surgical training knowledge retrieval must be associated with ability to apply it appropriately in real life situation and this needs an authentic learning, which refer to learning through actual task that is contrary to a traditional learning in which a student learns through interactive learning process without exposure to real life scenarios. Learning particularly in surgical training must therefore include an aspect of repeatedly done cases provided with novelty to test competency, varying level of pressure to perform and unexpected difficulties to counter. To achieve this systemic approach needs a comprehensive protocol in surgical skills training such as see one, do one and teach one model of learning skills (6).

Apprenticeship training that is learning onjob is the procedure of surgical training maintained in postgraduate training globally (7). The experience obtained by observing a 
surgical procedure has not been shown to be a substitute for proper training as see one, do one and teach one (6). Problems are worsening for hands on training with less available cases, respective supervision and increasing number of postgraduates. Another concern shown for postgraduate training is the lack of program evaluation, with feedback from major stakeholders inclusive of Ministry of Health, community, patients and the trainees. Portfolios from trainees during their training, observations reports from supervisors during the internship and inventory responded by the patients on trainee's performance, are the suggested tools for program evaluation in future.

Portfolio is an important tool for coaching and assessing authentic learning is the portfolio, which offers a systemic selfregulation as reflection (5). Key to an outcome-based postgraduate medical education is a well-defined curriculum, which elaborates goals and needs for postgraduate training, core content, teaching and learning methods, assessment, evaluation and accreditation of program. All those institutions that do not undergo evaluation of their program for lack of curriculum in practice of postgraduate medical education should target to achieve an outcome-based performance approach at institutional level. Rationalizing the practice of compiling portfolio in postgraduate training in Otolaryngology and Head-Neck Surgery the outcome-based competence can be seen as an evidence of a successful program of Masters' of surgery in this discipline. The objective of program is to produce performing specialist in this surgical discipline. However, the acknowledgement of competence of surgeons should come from the stakeholders rather than the institution producing them. Educational strategies and approaches adapted for surgeon's training in any discipline primarily rely on the educational continuum ultimate of which is the continuing medical education of an on-job-learning. To achieve this postgraduate medical education program needs to be well structured and truly student centered in practice. In postgraduate training emphasis must be given to continuous professional development integrated with outcomebased objective and self-directed learning strategy. The self-directed learning however should not be left without accountability and to achieve this we need to bring selfregulation in self-reflective approach in postgraduate training.

Learning to master surgical skill in postgraduate training is a performance task, which is best acquired in an on-job training and therefore assessment to declare who successfully have accomplished the task is not simple to decide merely on summative assessment. Like any extended performance task learning of surgical procedures not only rely on product but also on process of the training. Assessment of these extended performance task is always time consuming both for students to do and teachers to rate. Learning of surgical skills as performance task should focus on measuring the complex achievement that cannot be measured well by objective tests (2). A rating of trainees acquiring surgical skills should primarily base on directly observable behavior. Passing a summative assessment cannot guarantee a trainee's performance abilities and most of the classroom test, no matter how valid and reliable those are cannot determine learning outcome of a surgical training program that can be generalized. This is a significant point, which is now critically questioned by many stakeholders who have focused their eyes on competence of graduating doctors. This gives us food for thought to consider values of certified surgeons produced as a result of assessment based on qualitative rating of direct observation versus summative assessments based on quantitative measurement tools albeit reliable and valid.

Analyzing the portfolios compiled by trainees with a semi-structured format in this study has at least established that the students are capable of gauging and assessing their own competence in a self- 
reflective manner. Sufficient mentor's feedback and timely issued instructions to address individual or collaborative need is felt essential to achieve the out-come objectives of such a skills-based training program. A semi-structured interview of randomly selected seven trainees followed by portfolio analysis of 28 trainees has also endorsed the self-reflective-abilities a meaningful learning tool. However, expected to compile true reflection on own performance has shown reservations towards its use as an assessment tool by most trainees.

Appreciating the values of assessment of complex achievement as performance tasks, a purposeful working portfolio with instructional and assessment-intend can bridge the gap in making decision using more objective quantitative measurement tests as summative assessment and the less practiced qualitative observational rating as formative assessment. A triangulation of these two assessments in standard setting strategy for decision-making should now seriously be considered. Compiling portfolio by trainees and evaluating those with a backdrop of direct observation by the immediate supervisors in training though is time consuming but worth trying for a postgraduate training program. However, as is true of any instructional tool, portfolios have both strengths and weaknesses (2). The most applauded strength of a portfolio is in its role in triangulating it with more objective measurement tools and the selfreflective and the elf-evaluating skills developed by the trainees. And the obvious weakness is the time and labour intensive efforts required to complete and evaluate this document.

The evaluation of self-reflection portfolio for postgraduate medical education of the Master's of Surgery Program at School of Medical Sciences, University Science Malaysia is carried out in 5 steps to achieve the out-come objective of training in thyroid surgery module (see figure 1) as: 1) Observation report from the immediate supervisor with comments on knowledge, skills and attitude adequate for recommending to allow independent practice in thyroid surgery. 2) Hands-on experience with authentic learning claimed as self-reflection and evaluated as supervisor's report in portfolio. 3) Growth of learning evident from role-by-role responsibilities acquired in training evaluated. 4) Self-reflection portfolio confirmatory to above steps. 5) Summative assessment as a pre-requisite. 6) JCST and Director Hospital certification conferred to individual trainee on successfully accomplished all criteria set for training in thyroid surgery keeping view the safety of community subsequently exposed to those certified. To achieve the desired feedback for regular program evaluation, the portfolio entries are required to be structured in sections for all roles before considered for certification of independent practice in any module for that matter.

\section{Conclusion}

Clear portfolio structure, its evaluation and a timely delivered instruction from supervisors are the crucial factors in compiling portfolio for formative assessment of postgraduate trainees in medical education. Students must learn how to compile a portfolio and benefit from mentor's instructions as an essential support to this learning process. Reflective skills are essential to both learning from practice and learning for life long. Introduction of portfolio in a structured clinical skills program in medical education will help to produce competent doctors as expected by stakeholders.

The introduction of portfolio in a structured postgraduate training in thyroid surgery was an interesting experience both for trainees and trainers. Reflective abilities by itself were found an important skill to learn and follow in meeting the objectives of personal development plan by trainees. After closely studying the self-reflections about each 
structured items in portfolio we conclude that it helped trainees to work systemically with an opportunity to adjust their actions by revising learning objectives. Evaluation of trainee's portfolio and on time relevant instructions has not only improved the program as truly structured but has also benefited individual trainee in acquiring surgical skills required for thyroid patients.

\section{References}

1. Peggy $A E$, Timothy JN. The expert teacher: Strategic, self-regulation and reflective. Instructional Science. 1996; 24: 124

2. Robert LL, Miller MD. Portfolios in: Measurement and assessment in teaching. Pearson Education Inc. $3^{\text {rd }}$ edn. 2005: pp. 279-304

3. Snadden D, Thomas ML, Challis M. The Use of Portfolio-based Learning in Medical Education, AMEE Medical Education Guide No 11 (revised). Dundee: Association for Medical Education in Europe, 1999.

4. Pitts J, Coles C, Thomas P. Enhancing reliability in portfolio assessment: 'shaping' the portfolio. Medical Teacher. 2001; 23 (4): 351-355.

http://dx.doi.org/10.1080/01421590120057 021

5. Erick WD, Jan VT, Jan DV, Cess PM. Use of portfolio in early undergraduate medical training. Medical Teacher. 2003; 25 (1): 1419.

6. Eugene JFMC, Glenn R, Wendy M, Charles P, Richard R. (1999) The Effects of Modeling on Learning a Simple Surgical Procedure: See One, Do One or See Many, Do One? Advances in Health Sciences Education. 1999; 4 : 123-143 http://dx.doi.org/10.1023/A:100976321021 2

7. Gunderman RB. Educational Technique: Achieving Excellence in Medical Education. Springer Science London Publisher, 2006: pg. 81-92.

8. Friedus H. Mentoring portfolio development. In: N. Lyons (Ed.) With
Portfolio in Hand: Validating the New Teacher Professionalism. New York; Teachers College Press, 1998: pg. 51-68.

9. Wolf K, Whinery B, Hagerty P. (1995) Teaching portfolios and portfolio conversations for teacher educators and teachers. Action in teacher education. 1995; 17 (1): 30-39.

10. Wade RC, Yarbourgh DB. (1996) Portfolios: a tool for reflective thinking in teacher education? Teaching \& Teacher Education. 1996; 12 (1): 63-79 http://dx.doi.org/10.1016/0742051X(95)00022-C

11. Carrol JA, Potthoff D, Huber T. (1996) Learning from three years of portfolio use in teacher education. Journal of Teacher

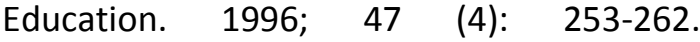
http://dx.doi.org/10.1177/00224871964740 03

12. Murphy S, Bergamini J, Rooney P. The impact of large-scale portfolio assessment programs on classroom practice: case studies of the new standards field trial portfolio. Educational Assessment. 1997; 4 (4):

297-233 http://dx.doi.org/10.1207/s15326977ea040 4_2

13. Driessen EW, Vleuten CPM. Matching student assessment to problem-based learning: lessons from experience in a law faculty. Studies in Continuing Education. 2000; 22(2); 235-248 http://dx.doi.org/10.1080/713695731

14. Beijaard D, Driessen EW, Van Tartwijk J, Van Der Vleuten CPM. (2002) Portfolio's erder uitgewerkt (Further development of portfolios). In: EW Driessen, D Beijaard, J Van Tartwijk, CPM van der Vleuten (Eds) Portfolios. Grogningen; Wolters-Noordhoff 2002: pp. 119-136

15. Norman GR. Vleuten CPM, Graaf ED. (1991). Pitfalls in the pursuit of objectivity: issues of validity, efficiency and acceptability. Medical Education. 1991; 25: $119 . \quad$ http://dx.doi.org/10.1111/j.13652923.1991.tb00037.x 
Short video on an operative procedure including instruments by lecturer

Collaborative video sessions of trainees teaching and leaming from each other (Seniors teaching the juniors)

Consultant performing surgery while trainees either assisting or observing

Allowing them to perform few steps under supervision

$$
\downarrow
$$

Trainees attempting initial steps and supervisors joining in the middle of surgery

Senior registrar performing under direct supervision and doing most of surgical procedures

Hands on as independent surgeon and $1^{\text {st }}$ and $2^{\text {nd }}$ assistants

Senior registrar performing the surgery, year I observing and year II/III/IV assisting

(Consultant available in premises of operation theatre to join surgery close to completion)

Senior registrar performing independently with a back up support of consultant in office with whom he can discuss difficulties encountered latter in an informal or formal meeting

Figure 2: Steps of the protocol practiced in surgical skills training of thyroid patient in ORL

Table 1: Year of training with respective assigned role as surgeon in thyroidectomy in ORL

\begin{tabular}{llccc}
\hline \multicolumn{1}{c}{$\begin{array}{c}\text { Type of the surgical } \\
\text { procedure in thyroid }\end{array}$} & \multicolumn{2}{c}{ Role as surgeon and number of trainees (year of training) } \\
& As an & As first & As second & As principal \\
& observer & assistant & assistant & Surgeon \\
\hline Lobectomy & 2 (year I) & 1 (year II) & 1 (year III) & 1(S. Registrar) \\
Subtotal thyroidectomy & 2 (year I) & 1 (year II) & 2 (year III) & 2 (S. Registrar) \\
N. total thyroidectomy & 1 (year I) & 1 (year II) & 2(year III / IV) & 2 (S. Registrar) \\
Total throidectom6 & 1 (year I) & 1 (year II) & 3 (year III/IV) & 2 (S. Registrar) \\
\hline
\end{tabular}

Table 2: Trainees apprehensions about knowledge and procedure of thyroidectomy in ORL

\begin{tabular}{|c|c|c|c|c|}
\hline \multirow{2}{*}{$\begin{array}{l}\text { No } \\
1\end{array}$} & \multirow{2}{*}{$\begin{array}{l}\text { The structured items } \\
\text { Prior concern about how } \\
\text { operation will do }\end{array}$} & \multicolumn{3}{|c|}{ Trainees out-come opinion (frequency) } \\
\hline & & $\begin{array}{l}\text { Apprehensive } \\
\text { (18) }\end{array}$ & $\begin{array}{l}\text { Straight case } \\
\text { (7) }\end{array}$ & $\begin{array}{l}\text { Not sure } \\
\text { (3) }\end{array}$ \\
\hline 2 & $\begin{array}{l}\text { Anticipation about diagnosis and } \\
\text { operation }\end{array}$ & $\begin{array}{l}\text { Agreed with } \\
\text { (20) }\end{array}$ & $\begin{array}{l}\text { Disagreed with } \\
\text { (3) }\end{array}$ & $\begin{array}{l}\text { Not sure } \\
\text { (5) }\end{array}$ \\
\hline 3 & $\begin{array}{l}\text { Prior knowledge of the surgical } \\
\text { anatomy }\end{array}$ & $\begin{array}{l}\text { Adequate } \\
\text { (13) }\end{array}$ & $\begin{array}{l}\text { Inadequate } \\
\text { (9) }\end{array}$ & $\begin{array}{l}\text { Not sure } \\
\text { (6) }\end{array}$ \\
\hline 4 & $\begin{array}{l}\text { Previous exposure of similar } \\
\text { surgery }\end{array}$ & $\begin{array}{l}\text { Adequate } \\
\text { (17) }\end{array}$ & $\begin{array}{l}\text { Inadequate } \\
\text { (8) }\end{array}$ & $\begin{array}{l}\text { Not sure } \\
\text { (3) }\end{array}$ \\
\hline
\end{tabular}


Table 3: Trainees opinion about the working environment and their role in thyroidectomy

\begin{tabular}{llccc}
\hline No & $\begin{array}{l}\text { Structured items from } \\
\text { the portfolio }\end{array}$ & \multicolumn{2}{c}{ Trainees out-come opinion (frequency) } \\
\hline 1 & $\begin{array}{l}\text { Expected role assigned as a } \\
\text { surgeon }\end{array}$ & Satisfactory & Unsatisfactory & Not sure \\
& Knowing the steps of the & Well aware & Partly aware & Not aware \\
2 & operative procedure & $(11)$ & $(13)$ & $(4)$ \\
3 & Instructional support that I & On-time back up & Learning as a & Senior's \\
& liked about this surgery & from supervisor & team & attitude \\
& What I didn't like about this & Anesthetist & Patient's status & Difficulties \\
4 & surgery & interference & as well of & (15) \\
& & $(3)$ & $(1)$ & \\
\hline
\end{tabular}

Table 4: Trainees impression on his learning curve for thyroidectomy procedures in ORL

\begin{tabular}{llccc}
\hline No & The structured items & \multicolumn{2}{c}{ Trainees out-come opinion (frequency) } & \\
\hline 1 & My personal plan to & Same as planned & A changed plan & Not sure \\
operate on this case & $(22)$ & (3) & (3) \\
\hline 2 & My confidence towards my & Need more & Need backup & Need to work \\
role in this case & training & Support & independent \\
& & $(15)$ & $(22)$ & $(5)$ \\
\hline 3 & My learning outcome in & All opt. not the & Need more skills & Complication I \\
& this particular case & same & Practice & must know \\
& & $(11)$ & $(21)$ & (13) \\
\hline 4 & I am looking forward to do & Counseling the & More independent & Patient's audit \\
& further in this case & patient & work & (13) \\
& & $(2)$ & (7) & \\
\hline
\end{tabular}

Corresponding Author: Professor Dr Shahid Hassan, Medical Education/ Otorhinolaryngology Department, School of Medical Sciences, Universiti Sains Malaysia, Kubang Kerian, 16150 Kota Bharu, Kelantan, Malaysia.

Email: shahid@kb.usm.my,gorshahi@yahoo.com 
Appendix: Semi-structured format of self-reflective portfolio administered prior to structured portfolio for trainees acclimatization to compiling portfolio.

\begin{tabular}{|c|c|}
\hline & MY SELF-REFLECTIVE PORTFOLIO ON SURGICAL SKILLS IN THYROID SURGERY \\
\hline $\begin{array}{l}\text { Nam } \\
\text { Date }\end{array}$ & Surgical procedure \\
\hline $\begin{array}{l}\text { Inst } \\
\text { add } \\
\text { to } p\end{array}$ & $\begin{array}{l}\text { Please read each item in this semi-structured proforma carefully and give your remarks as brief text } \\
\text { queries in each item. Alternatively you may adopt a structured proforma as four clusters in table 1-4 } \\
\text { esponse using ( } \mathrm{V} \text { sign by pressing alt }+\mathrm{v} \text { ) choosing one or more options in each item. }\end{array}$ \\
\hline 1 & $\begin{array}{l}\text { My expectation for role in this surgery: (are you happy with the role assigned as surgeon, } 1^{\text {st }} \text { assistant } \\
\text { or } 2^{\text {nd }} \text { assistant and do you feel capable of this role?) } \\
\text { Comments: }\end{array}$ \\
\hline 2 & $\begin{array}{l}\text { My understanding with patient's problem: (are you well conversant with patient's pre-operative work- } \\
\text { up prior to your inclusion in the team?) } \\
\text { Comments: }\end{array}$ \\
\hline 3 & $\begin{array}{l}\text { My prior knowledge of surgical anatomy: (did you especially read for this case or relied on your prior } \\
\text { knowledge/experience) } \\
\text { Comments: }\end{array}$ \\
\hline 4 & $\begin{array}{l}\text { My confidence and previous exposure: (briefly describe your previous exposure (number of operations } \\
\text { attended) as observer or performing surgeon. interest in this surgery, enthusiasm, knowledge, skills } \\
\text { and attitude) } \\
\text { Comments: }\end{array}$ \\
\hline 5 & $\begin{array}{l}\text { My concerns about patient care in this case if included in team: (were you apprehensive about patient } \\
\text { care while performing as surgeon based on previous exposure and complications encountered while } \\
\text { assisting or operating?) } \\
\text { Comments: }\end{array}$ \\
\hline 6 & $\begin{array}{l}\text { My Anticipation towards the outcome in this case: (did you have any difference of opinion with regard } \\
\text { to diagnoses and operation procedure prior to surgery in this case and how do you compare it with the } \\
\text { ultimate outcome after the surgery. did the procedure go smooth as said by your seniors or turned } \\
\text { difficult as you suspected?) } \\
\text { Comments: }\end{array}$ \\
\hline 7 & $\begin{array}{l}\text { What did I like about performing this surgery: (did you find environment in which you perform } \\
\text { relaxing, encouraging and conducive for collaborative learning or discouraging beyond your } \\
\text { expectations?) } \\
\text { Comments: }\end{array}$ \\
\hline 8 & $\begin{array}{l}\text { What I did not like about performing this surgery: (in relation to your role in the team or from patient's } \\
\text { perspective, operation difficulty and complications, interdisciplinary (anesthetist and nurses) } \\
\text { cooperation or recovery problems) } \\
\text { Comments: }\end{array}$ \\
\hline 9 & $\begin{array}{l}\text { My immediate plan from learning perspective according to my role in this case: (how did you plan to } \\
\text { proceed once you were asked to operate as a team member?) } \\
\text { Comments: }\end{array}$ \\
\hline 10 & $\begin{array}{l}\text { Supervision required doing this surgery: (was previous training adequate for you to take up the } \\
\text { present role as surgeon in the team and what is your feeling about supervision required in } \\
\text { thyroidectomies) } \\
\text { Comments: }\end{array}$ \\
\hline 11 & $\begin{array}{l}\text { What I learned from this case: (analyze your professional development in thyroid and draw conclusion } \\
\text { from this analysis especially if you want a change learning objectives set for learning skills in thyroid } \\
\text { surgery) } \\
\text { Comments: }\end{array}$ \\
\hline 12 & $\begin{array}{l}\text { Further proposal or any other remarks: (something which needs reflection and is not covered under } \\
\text { those queries above and if included will help better training in thyroid surgery) } \\
\text { Comments: }\end{array}$ \\
\hline
\end{tabular}

